Journal of

NEUROINTERVENTIONAL SURGERY

\title{
Primary Endovascular Treatment of Post-irradiated Carotid Pseudoaneurysm at the skull base with Pipeline embolization device
}

\begin{tabular}{|r|l|}
\hline Journal: & Journal of NeuroInterventional Surgery \\
\hline Manuscript ID: & neurintsurg-2014-011154.R1 \\
\hline Article Type: & Original research \\
\hline Keywords: & Aneurysm, Complication, Flow Diverter, Hemorrhage, Vessel Wall \\
\hline \multicolumn{2}{|c}{} \\
\hline
\end{tabular}




\title{
Primary Endovascular Treatment of Post-irradiated Carotid Pseudoaneurysm at the skull base with Pipeline embolization device
}

\begin{abstract}
BACKGROUND: Post-irradiated carotid pseudoaneurysm at the skull base can cause lifethreatening blowout syndrome. Conventional treatments include parent vessel occlusion, endovascular coiling or covered stenting. Use of the Pipeline Embolization Device (PED) for pseudoaneurysm exclusion at the skull base is not well described. We report the clinical and angiographic outcome using multiple PED to treat recently ruptured radiation-induced carotid pseudoaneurysms at the skull base.
\end{abstract}

METHODS: Retrospective review of the clinical and angiographic records of patients who received PED as primary treatment for skull base carotid pseudoaneurysm from $1^{\text {st }}$ April 2011 to $31^{\text {st }}$ March 2013.

RESULTS: 7 patients were treated in the study period including five men and two women, with a mean age of 58 years (range: 47 to 65). Primary treatment with the PED alone, with adjunct coil embolization in 2 patients, achieved immediate hemostasis in all patients, with no pseudoaneurysm rebleeding after a mean follow-up of 15.3 months (range 4-24 months). One patient suffered from peri-procedural cerebral infarction. Delayed ICA occlusion secondary to instent thrombosis occurred in 3 patients, 1 of which had lacunar infarct and 2 remained asymptomatic.

CONCLUSION: Endovascular treatment with the PED was effective in excluding skull base post-irradiated carotid pseudoaneurysms and preventing recurrent blowout. However the risk of ischemic complications in this group of patients was high and our experience did not support the use of flow diverters as a first line treatment for this condition. 
RUNNING TITLE: Flow diverter for radiation-induced ICA aneurysms at the skull base

KEYWORDS: Carotid pseudoaneurysm, Radiotherapy, Endovascular procedures

\author{
ABBREVIATIONS: \\ CBS, carotid blowout syndrome \\ CT, computer tomography \\ DSA, digital subtraction angiography \\ ICA, internal carotid artery \\ PVO, parent artery occlusion (PVO) \\ PED, pipeline embolization device
}




\section{INTRODUCTION}

Radiotherapy is an effective treatment for head and neck cancers but it may also cause long-term damages to the carotid arteries, resulting in arterial stenosis, occlusion or the formation of pseudoaneurysms.(1) Post-irradiated carotid pseudoaneurysms after radiotherapy for nasopharyngeal cancer typically occur at the petrous and laceral carotid artery, and may present with life-threatening epistaxis due to carotid blowout syndrome (CBS).(2) Recognized treatments for these lesions include parent artery occlusion (PVO) with or without revascularization, endovascular coil embolization, and covered stenting. $(3,4)$ The introduction of endovascular flow-diverters provides another potential treatment option. The pipeline embolization device (PED) is one of these flow-diverters with 30-35\% surface coverage, designed to achieve curative reconstruction of intracranial arteries that harbor aneurysms with challenging morphologies.(5, 6) Outcome in the treatment of non-ruptured intracranial aneurysms was satisfactory.(7-10) However, its efficacy for ruptured pseudoaneurysm, in particular that with an extradural location at the skull base is unclear. We present our experience with the PED in the treatment of patients with ruptured post-irradiated ICA pseudoaneurysms at the skull base.

\section{PATIENTS AND METHODS}

\section{Patients}

This is a retrospective study of prospectively collected data of all-inclusive patients treated with the PED for radiation-induced extracranial ICA pseudoaneurysms at our institution from April 2011 to March 2013. All patients had history of nasopharyngeal carcinoma primarily treated with prior external radiotherapy involving the skull base, and had developed ICA pseudoaneurysms within the irradiated fields at the skull base. All presented with severe epistaxis due to aneurysm rupture. Initial hemostasis was achieved by means of nasal packing, followed by diagnostic digital subtraction angiography (DSA) and PED reconstruction on an emergency basis within 24 hours. 


\section{Procedure and Follow-up}

Immediately before PED placement, patients were given 300mg of clopidogrel and $300 \mathrm{mg}$ of aspirin. Clopidogrel (75mg daily) was maintained for at least one week and aspirin (80mg daily) was given for six months after surgery. Low molecular weight heparin was given at $1 \mathrm{mg} / \mathrm{kg}$ every 12 hours and was maintained for 24 hours after surgery. Intravenous prophylactic antibiotics (amoxicillin-clavulanate $1.2 \mathrm{~g}$ and metronidazole $500 \mathrm{mg}$ ) were given on induction of general anesthesia, and maintained for one week post-operatively.

The PED (ev3 Inc, Plymouth, MN, USA) was deployed in the standard manner using transfermoral arterial approach. Additional PEDs were placed telescopically with the overlapping segment covering the entire aneurysm neck for double coverage if there was inadequate contrast stasis in the aneurysm sac. (Figure 3b) Coils were deployed prior to placement of PED when there was ongoing contrast extravasation or the aneurysm sac was large to facilitate hemostasis and thrombosis of pseudoaneurysm. (Figure 2b) A check DSA was performed to ensure that the entire aneurysm neck was covered, and to exclude acute in-stent thrombosis, distal embolism and contrast extravasation through the aneurysm.

\section{Outcome assessment}

We assessed the efficacy of immediate and mid-term hemostasis, and the occurrence of periprocedural complications including ischemic and hemorrhagic neurological events. Follow-up DSA or computer tomography (CT) angiograms were performed to assess aneurysm obliteration, delayed in-stent stenosis and device migration. Patients' neurologic outcomes were assessed using the modified Rankin's Score.

\section{RESULTS}

\section{Patient characteristics}


There were seven patients, including five men and two women, with a mean age of 58 years (range: 47-65). Their clinical features, aneurysm characteristics, and treatment outcomes were summarized in Table 1. Four patients' primary malignant diseases were in remission; three suffered from recurrent cancers at the time of presentation. The pseudoaneurysms occurred in the petrous and laceral portions of the ICA in five and two patients, respectively. The median aneurysm size was $2.3 \mathrm{~mm}$ (range: $1.2-12.2 \mathrm{~mm}$ ) All except two patients presented without a prior diagnosis of ICA pseudoaneurysm. Patient 1 had reconstitution of pseudoaneurysm one year after covered stent placement. Patient 2 had undergone treatment for a left-sided pseudoaneurysm at another center 3 months prior to presenting to us with a ruptured right-sided lesion. 


\begin{tabular}{|c|c|c|c|c|c|c|c|c|c|}
\hline Patient & $\begin{array}{l}\text { Ag } \\
\text { e }\end{array}$ & $\begin{array}{l}\text { Aneurysm } \\
\text { location }\end{array}$ & $\begin{array}{l}\text { No. of PED } \\
\text { (size) }\end{array}$ & $\begin{array}{l}\text { Aneurys } \\
\text { m size } \\
\text { (max. } \\
\text { diameter } \\
\text { x dome } \\
\text { height) }\end{array}$ & $\begin{array}{l}\text { Adjuva } \\
\text { nt coils }\end{array}$ & $\begin{array}{l}\text { Complicati } \\
\text { ons }\end{array}$ & $\begin{array}{l}\text { Angiogram } \\
\text { findings(months } \\
\text { post-operation) }\end{array}$ & $\begin{array}{l}\text { Follo } \\
\text { w up } \\
\text { (mont } \\
\text { hs) }\end{array}$ & $\begin{array}{l}\text { Outcome at } \\
\text { last follow up }\end{array}$ \\
\hline 1 & $40 \mathrm{~s}$ & $\begin{array}{l}\text { Right petrous } \\
\text { ICA }\end{array}$ & $1(4.5 \times 20 \mathrm{~mm})$ & $1.2 \times 0.9 \mathrm{~mm}$ & - & - & $\begin{array}{l}\text { CTA (7): Patent } \\
\text { ICA, obliterated } \\
\text { aneurysm }\end{array}$ & 18 & $\begin{array}{l}\text { Died of } \\
\text { brainstem } \\
\text { hemorrhage }\end{array}$ \\
\hline 2 & $50 \mathrm{~s}$ & $\begin{array}{l}\text { Right petrous } \\
\text { ICA }\end{array}$ & $\begin{array}{l}2(4 \times 20 \\
3.75 \times 20 \mathrm{~mm})\end{array}$ & $\begin{array}{l}2.2 \mathrm{x} \\
1.3 \mathrm{~mm}\end{array}$ & - & $\begin{array}{l}\text { Multiple } \\
\text { cerebral } \\
\text { infarctions }\end{array}$ & Not done & 11 & $\begin{array}{l}\text { Died of tumor } \\
\text { progression }\end{array}$ \\
\hline 3 & $50 \mathrm{~s}$ & $\begin{array}{l}\text { Left laceral } \\
\text { ICA }\end{array}$ & $2(5 \times 20 \mathrm{~mm})$ & $2.5 \times 1.6 \mathrm{~mm}$ & - & - & $\begin{array}{l}\text { CTA (1): Patent } \\
\text { ICA, obliterated } \\
\text { aneurysm } \\
\text { CTA (8): } \\
\text { occluded ICA }\end{array}$ & 24 & $\mathrm{mRS} 1$ \\
\hline 4 & $60 \mathrm{~s}$ & $\begin{array}{l}\text { Right petrous } \\
\text { ICA }\end{array}$ & $\begin{array}{l}2 \\
(4.25 \times 20,4 \times 20 \\
\mathrm{mm})\end{array}$ & $1.8 \times 6.0 \mathrm{~mm}$ & $\begin{array}{l}\text { GDC } \\
\text { coils }\end{array}$ & - & Not done & 4 & $\begin{array}{l}\text { Died of } \\
\text { metastatic breast } \\
\text { cancer }\end{array}$ \\
\hline 5 & $60 s$ & $\begin{array}{l}\text { Left petrous } \\
\text { ICA }\end{array}$ & $\begin{array}{l}2(4.5 \times 30, \\
3.75 \times 20 \mathrm{~mm})\end{array}$ & $\begin{array}{l}12.2 \times 6.6 \mathrm{~m} \\
\mathrm{~m}\end{array}$ & $\begin{array}{l}\text { Matrix } \\
\text { coils }\end{array}$ & - & $\begin{array}{l}\text { DSA (8): Patent } \\
\text { ICA obliterated } \\
\text { aneurysm }\end{array}$ & 14 & $\begin{array}{l}\text { Died of } \\
\text { pneumonia }\end{array}$ \\
\hline 6 & $60 \mathrm{~s}$ & $\begin{array}{l}\text { Right petrous } \\
\text { ICA }\end{array}$ & $\begin{array}{l}2 \\
(5 \times 35,4.5 \times 20 \mathrm{~m} \\
\mathrm{m})\end{array}$ & $3.3 \times 1.7 \mathrm{~mm}$ & - & $\begin{array}{l}\text { Delayed ICA } \\
\text { thrombosis } \\
\text { and lacunar } \\
\text { infarct at } 10 \\
\text { months }\end{array}$ & $\begin{array}{l}\text { CTA (3): Patent } \\
\text { ICA, obliterated } \\
\text { aneurysm } \\
\text { DSA (10): } \\
\text { occluded ICA }\end{array}$ & 14 & $\begin{array}{l}\text { Died of tumor } \\
\text { progression }\end{array}$ \\
\hline 7 & $40 s$ & $\begin{array}{l}\text { Right laceral } \\
\text { ICA }\end{array}$ & $\begin{array}{l}3(4 \times 20 \\
3.75 \times 20 \\
4 \times 30 \mathrm{~mm})\end{array}$ & $2.3 \times 1.8 \mathrm{~mm}$ & - & - & $\begin{array}{l}\text { DSA (5): Right } \\
\text { ICA occlusion }\end{array}$ & 22 & $\mathrm{mRS} 1$ \\
\hline
\end{tabular}

Abbreviations: CTA, CT angiogram; DSA, digital subtraction angiogram; GDC, Guglielmi detachable coil; ICA, internal carotid artery; mRS, modified Rankin scale; NPC, nasopharyngeal carcinoma; 


\section{Procedural and clinical outcomes}

Five patients received two PEDs each, one patient received one device, and another had three devices. Adjuvant coil embolization was used in two patients. The median operation time was 85 minutes (range: 50-236). The median hospital stay was 21 days (range: 4-90). (Table 1) There was no procedure-related mortality. Immediate hemostasis was achieved with DSA confirmed no filling of the pseudoaneurysm in all patients. None experienced recurrent pseudoaneurysm bleeding after a mean clinical follow-up period of 15.3 months (range 4-24 months).

The patient who had a contralateral pseudoaneurysm treated previously (Patient 2) suffered from ischemic cerebral infarctions after PED placement at our center. There was left ICA occlusion, presumably due to previous treatment at another center, as well as $70 \%$ right common carotid artery and 50\% right proximal ICA stenosis. We performed right ICA angioplasty and stenting for the stenosis prior to PED placement. This patient developed multiple ischemic infarctions afterwards which were likely secondary to endovascular manipulations within a precarious circulation. (Figure 1) There was no other peri-procedural complication.

Follow-up angiographic studies were performed in five patients. Patient 2 as described above declined further investigation, and died of progression of nasopharyngeal cancer 11 months after PED treatment. Another patient (Patient 4) developed pleural effusion secondary to lymphangitis carcinomatosis and carcinoma of the breast and died four months after PED placement. Of the remaining five patients with angiographic follow up, there were no reconstitutions of aneurysm. Two patients (Patients 2 and 7) had asymptomatic in-construct thrombosis at 5 and 7 months respectively. Patient 6 had obliterated aneurysm and patent ICA on CT angiogram at 3 months and remained asymptomatic until at 10 months when a new lacunar infarction at ipsilateral internal capsule developed. There was good neurological recovery. Subsequent DSA showed occluded ipsilateral Right ICA. Their neurologic outcomes were listed in Table 1. Figure 2 and 3 illustrate two patients (Patient 5 and 6 ) who had complete aneurysm obliterations on initial follow up angiogram. 


\section{DISCUSSION}

The primary goal of treatment for radiation-induced ICA pseudoaneurysm is the prevention of life-threatening CBS. Since these aneurysms commonly occur at the extradural segments of the ICA located at the skull base, they are rarely amenable to surgical clipping. Endovascular intervention is currently the treatment of choice. PVO in patients with adequate collateral supplies, confirmed on balloon occlusion test (BTO), has been used by many authorities with satisfactory outcome.(11) However, a subgroup of these patients may still develop severe ischemic complications after PVO which indicates the advantage of preserving the native circulation.(12) PVO with extracranial-intracranial arterial bypass is another option but the procedure is technically demanding, and sometimes challenging for this group of often debilitated patients.(13) This cohort of patients typically received repeated radiotherapy for nasopharyngeal cancer and frequently there were bilateral radiation-induced carotid stenosis putting the cerebral circulation at risk. We did not perform routine BTO as we aim to preserve of parent artery with endovascular treatments whenever possible.

Established endovascular therapies for pseudoaneurysm while preserving parent artery include coil embolization and covered-stent exclusion. Coil embolization, for example, can achieve hemostasis effectively.(4) However, the morphology of some of these lesions (e.g., wide-based or blister-like pseudoaneurysm) may not be suitable for coiling, as were the case in five of our patients. Moreover, these pseudoaneurysms lack a true wall histologically and are commonly surrounded by radionecrotic bone, coil extrusion and rebleeding may occur.(14, 15) Our center had previously reported the use of self-expandable covered stent-graft in such patients, which has the advantage of achieving immediate reconstruction of the vessel wall.(15) The initial angiographic outcomes were satisfactory but the presence of tumorous or infected tissues may result in delayed complications such as in-stent thrombosis and infections.(15-17) Chang et al treated 11 patients with CBS using stent-grafts. Immediate hemostasis was achieved in all patients but five subsequently suffered from rebleeding.(2) Since 2011, we elect to use flow diverter because of its high metal surface coverage, better maneuverability compared with covered-stents, and because self-expanding covered-stents are no longer available at our locality. 
Flow diverters had proven to be an effective treatment for unruptured intracranial aneurysms.(59, 18-21) A recent meta-analysis including 1654 intracranial aneurysms found a complete occlusion rate of $76 \%$ at 6 -months. (22) The PED is known to reduce blood flow within an aneurysm sac to the point of stagnation and thrombosis, and can facilitate neointimal remodeling of the parent artery. Use of the PED for carotid pseudoaneurysm intracranially as well as at the skull base had been reported with mixed results. (23-28) Amenta et al. reported a successful PED treatment for traumatic carotid pseudoaneurysm with a follow up of 4 months.(26) Nerva et al. reported 2 patients with iatrogenic carotid pseudoaneurysm at the cavernous segment after endoscopic transsphenoidal surgery treated with PED and achieved complete aneurysm occlusion. (27) However, early rebleeding after PED treatment in pseudoaneurysms could occur.(24, 28) Our results provide further information on applying PED for post-irradiated carotid pseudoaneurysms located at the skull base. For the 7 patients we treated, all achieved the primary goal of hemostasis and pseudoaneurysm exclusion.

A single PED has 30 to $35 \%$ surface area coverage. To secure the pseudoaneurysm and prevent re-rupture, we deliberately used multiple PEDs in 6 of the patients with telescopic placement in an attempt to increase coverage over the aneurysm neck. We also used adjuvant coiling when there was ongoing contrast extravasation or when the aneurysm sac was large. This was necessary in two of our seven patients. This approach was similar to the successful experience by Amenta et al., and Nerva et al., which may suggest the efficacy of multiple flow-diverters in achieving a covered-stent effect to exclude the pseudoaneurysm.(26, 27) Although none of our patients suffered from recurrent hemorrhages after a mean follow-up of over 15 months, the importance of long-term follow-up cannot be over-emphasized. It is also important to emphasize the need for obtaining temporary control of the epistaxis by means of surgical packing prior to PED placement; the latter performed in the presence of active CBS is neither safe nor feasible.

Use of the PED in the context of a recently ruptured intracranial aneurysm causing subarachnoid haemorrhage has also been reported but remains controversial.(29-34) The PED does not always result in an immediate and complete cessation of intrasaccular blood flow. This may lead to rebleeding especially where there is no coil to protect the aneurysm dome. MaAullifffe et al treated 11 patients with recently ruptured intracranial aneurysms. Two patients suffered from 
rebleeding and the author cautioned against this application.(33) Another concern is the need for dual antiplatelet agents after PED placement, complicating the risk of rebleeding and hydrocephalus management.

Despite the reasonable results for preventing rebleeding, our patients demonstrated a higher rate of ischemic compications than generally reported for the PED. Patient 2 had an occluded left carotid artery and multifocal stenosis of the right carotid artery due to previous radiation. In order to secure the pseudoaneurysm, we had to perform angioplasty and negotiate through the proximal stenosed carotid artery before deploying the PED. He suffered from peri-procedural infarct. In addition, 3 patients developed delayed stent thrombosis, of which 1 was symptomatic.

Symptomatic infarctions secondary to delayed in-stent thrombosis similar to Patient 6 have been reported. $(6,35)$. Patient 6 was put on double anti-platelet agents since PED placement, clopidogrel was stopped 2 weeks later and aspirin maintained for 6 months. This patient remained asymptomatic for 4 months after cessation of all anti-platelet therapy, and only developed lacunar infarct with in-construct thrombosis at 10 months after initial PED placement.

We surmise this worrisome rate of ischemic complications may be due to the inadequate antiplatelet regimen we used in this particular group of patients, compounded with delayed endothelialization of irradiated parent arteries as well as use of multiple PEDs. The optimal duration for antiplatelet treatment after flow diverters is unclear. For elective treatment of unruptured aneurysms, we routinely prescribe double antiplatelet agents for at least 3 months followed by aspirin for 6 months in total. However, in the present study, the patients were constantly at risk of life-threatening bleeding from the pseudoaneurysm, the osteonecrotic nasopharynx or recurrent nasopharyngeal tumor. We therefore were much more prudent with antiplatelet agents and only used double antiplatelet agents for the initial 1-4 weeks followed by aspirin alone subsequently. Although we did not encounter hemorrhagic complications, this overcautious antiplatelet regimen led to a high ischemic risk. The high delayed in-stent thrombosis rate demonstrated in our series highlighted the importance of adequate antiplatelet treatment. In light of the significant ischemic risk, long term or even life-long antiplatelet agents may be indicated after PED placement, in particular in irradiated arteries, although the hemorrhagic risk remains a concern. 


\title{
CONCLUSION
}

\begin{abstract}
Radiation-induced ICA pseudoaneurysms at the skull base are challenging conditions for which endovascular intervention is currently the treatment of choice. The present study indicates that the PED as a primary emergency treatment was effective in excluding recently ruptured pseudoaneurysm and preventing rebleeding. However, there was a significant risk of ischemic complications in this group of patients with irradiated arteries. Adequate antiplatelet agents were mandatory although hemorrhagic risk remain a concern. Our results did not support the use of flow diverters as a first line treatment for this condition over coil embolization or covered stent, and it should be used with discretion.
\end{abstract}

\section{REFERENCES}

1. Murros KE, Toole JF. The effect of radiation on carotid arteries. A review article. Arch Neurol. 1989;46(4):449-55. Epub 1989/04/01.

2. Chang FC, Lirng JF, Luo CB, Wang SJ, Wu HM, Guo WY, et al. Patients with head and neck cancers and associated postirradiated carotid blowout syndrome: endovascular therapeutic methods and outcomes. J Vasc Surg. 2008;47(5):936-45. Epub 2008/03/11. 3. Ellens DJ, Hurley MC, Surdel D, Shaibani A, Pelzer H, Bendok BR. Radiotherapyinduced common carotid pseudoaneurysm presenting with initially occult upper airway hemorrhage and successfully treated by endovascular stent graft. Am J Otolaryngol. 2010;31(3):195-8. Epub 2009/12/18.

4. Cheng KM, Chan CM, Cheung YL, Chiu HM, Tang KW, Law CK. Endovascular treatment of radiation-induced petrous internal carotid artery aneurysm presenting with acute haemorrhage. A report of two cases. Acta Neurochir (Wien). 2001;143(4):351-5; discussion 5-6. Epub 2001/07/05.

5. Lylyk P, Miranda C, Ceratto R, Ferrario A, Scrivano E, Luna HR, et al. Curative endovascular reconstruction of cerebral aneurysms with the pipeline embolization device: the Buenos Aires experience. Neurosurgery. 2009;64(4):632-42; discussion 42-3; quiz N6. Epub 2009/04/08.

6. Szikora I, Berentei Z, Kulcsar Z, Marosfoi M, Vajda ZS, Lee W, et al. Treatment of intracranial aneurysms by functional reconstruction of the parent artery: the Budapest experience with the pipeline embolization device. AJNR Am J Neuroradiol. 2010;31(6):1139-47. Epub 2010/02/13. 
7. Deutschmann HA, Wehrschuetz M, Augustin M, Niederkorn K, Klein GE. Long-term follow-up after treatment of intracranial aneurysms with the Pipeline embolization device: results from a single center. AJNR Am J Neuroradiol. 2012;33(3):481-6. Epub 2011/12/14.

8. de Barros Faria M, Castro RN, Lundquist J, Scrivano E, Ceratto R, Ferrario A, et al. The role of the pipeline embolization device for the treatment of dissecting intracranial aneurysms. AJNR Am J Neuroradiol. 2011;32(11):2192-5. Epub 2011/09/03.

9. Becske T KD, Saatci I, McDougall CG, Szikora I, Lanzino G, Moran CJ, Woo HH, Lopes DK, Berez AL, Cher DJ, Siddiqui AH, Levy EI, Albuquerque FC, Fiorella DJ, Berentei Z, Marosfoi M, Cekirge SH, Nelson PK. Pipeline for uncoilable or failed aneurysms: results from a multicenter clinical trial. Radiology. 2013;267(3):858-68. doi: 10.1148/radiol.13120099. Epub 2013 Feb 15.

10. Yu SC, Kwok CK, Cheng PW, Chan KY, Lau SS, Lui WM, et al. Intracranial aneurysms: midterm outcome of pipeline embolization device--a prospective study in 143 patients with 178 aneurysms. Radiology. 2012;265(3):893-901. Epub 2012/09/22.

11. Wong GK, Poon WS, Chun Ho Yu S. Balloon test occlusion with hypotensive challenge for main trunk occlusion of internal carotid artery aneurysms and pseudoaneurysms. $\mathrm{Br} \mathrm{J}$ Neurosurg. 2010;24(6):648-52. Epub 2010/07/17.

12. Dare AO, Chaloupka JC, Putman CM, Fayad PB, Awad IA. Failure of the hypotensive provocative test during temporary balloon test occlusion of the internal carotid artery to predict delayed hemodynamic ischemia after therapeutic carotid occlusion. Surg Neurol. 1998;50(2):14755; discussion 55-6. Epub 1998/08/13.

13. Yasuda H, Kuroda S, Ushikoshi S, Kato T, Houkin K, Iwasaki Y, et al. Combined surgical and endovascular treatment of infected pseudoaneurysm after carotid endarterectomy. Case report. Neurol Med Chir (Tokyo). 2005;45(1):37-40. Epub 2005/02/09.

14. Lin HW, Tierney HT, Richmon JD, Mark EJ, Deschler DG. Extrusion of embolization coils through the carotid artery in a radiated neck. Auris Nasus Larynx. 2010;37(3):390-3. Epub 2009/08/28.

15. Auyeung KM, Lui WM, Chow LC, Chan FL. Massive epistaxis related to petrous carotid artery pseudoaneurysm after radiation therapy: emergency treatment with covered stent in two cases. AJNR Am J Neuroradiol. 2003;24(7):1449-52. Epub 2003/08/15.

16. Pyun HW, Lee DH, Yoo HM, Lee JH, Choi CG, Kim SJ, et al. Placement of covered stents for carotid blowout in patients with head and neck cancer: follow-up results after rescue treatments. AJNR Am J Neuroradiol. 2007;28(8):1594-8. Epub 2007/09/12.

17. Simental A, Johnson JT, Horowitz M. Delayed complications of endovascular stenting for carotid blowout. Am J Otolaryngol. 2003;24(6):417-9. Epub 2003/11/11.

18. Wong GK, Kwan MC, Ng RY, Yu SC, Poon WS. Flow diverters for treatment of intracranial aneurysms: current status and ongoing clinical trials. J Clin Neurosci. 2011;18(6):737-40. Epub 2011/04/26.

19. Lubicz B, Collignon L, Raphaeli G, De Witte O. Pipeline flow-diverter stent for endovascular treatment of intracranial aneurysms: preliminary experience in 20 patients with 27 aneurysms. World Neurosurg. 2011;76(1-2):114-9. Epub 2011/08/16.

20. Puffer RC, Kallmes DF, Cloft HJ, Lanzino G. Patency of the ophthalmic artery after flow diversion treatment of paraclinoid aneurysms. J Neurosurg. 2012;116(4):892-6. Epub 2012/01/10.

21. Colby GP, Lin LM, Gomez JF, Paul A, Huang J, Tamargo RJ, et al. 100 Immediate procedural outcomes in 35 consecutive pipeline embolization cases: a single-center, single-user experience. Neurosurgery. 2012;71(2):E543. Epub 2012/07/20. 
22. Brinjikji W, Murad MH, Lanzino G, Cloft HJ, Kallmes DF. Endovascular treatment of intracranial aneurysms with flow diverters: a meta-analysis. Stroke. 2013;44(2):442-7. Epub 2013/01/17.

23. Rahal JP, Dandamudi VS, Heller RS, Safain MG, Malek AM. Use of concentric Solitaire stent to anchor Pipeline flow diverter constructs in treatment of shallow cervical carotid dissecting pseudoaneurysms. J Clin Neurosci. 2013. Epub 2014/01/15.

24. Kadkhodayan Y, Shetty VS, Blackburn SL, Reynolds MR, Cross DT, 3rd, Moran CJ. Pipeline embolization device and subsequent vessel sacrifice for treatment of a bleeding carotid pseudoaneurysm at the skull base: a case report. J Neurointerv Surg. 2013;5(5):e31. Epub 2012/07/31.

25. Kim JD, Barber SM, Diaz OM, Li HK, Jackson RE, Hall D, et al. Post-traumatic amaurosis secondary to paraophthalmic internal carotid artery pseudoaneurysm treated with pipeline embolization device. Journal of neuro-ophthalmology : the official journal of the North American Neuro-Ophthalmology Society. 2013;33(4):359-62. Epub 2013/10/31.

26. Amenta PS, Starke RM, Jabbour PM, Tjoumakaris SI, Gonzalez LF, Rosenwasser RH, et al. Successful treatment of a traumatic carotid pseudoaneurysm with the Pipeline stent: Case report and review of the literature. Surgical neurology international. 2012;3:160. Epub 2013/02/02.

27. Nerva JD, Morton RP, Levitt MR, Osbun JW, Ferreira MJ, Ghodke BV, et al. Pipeline Embolization Device as primary treatment for blister aneurysms and iatrogenic pseudoaneurysms of the internal carotid artery. J Neurointerv Surg. 2014. Epub 2014/03/01.

28. Wan WS, Lai V, Lau HY, Wong YC, Poon WL, Tan CB. Endovascular treatment paradigm of carotid blowout syndrome: Review of 8-years experience. Eur J Radiol. 2011. Epub 2011/02/12.

29. Martin AR, Cruz JP, Matouk CC, Spears J, Marotta TR. The pipeline flow-diverting stent for exclusion of ruptured intracranial aneurysms with difficult morphologies. Neurosurgery. 2012;70(1 Suppl Operative):21-8; discussion 8. Epub 2011/08/16.

30. Narata AP, Yilmaz H, Schaller K, Lovblad KO, Pereira VM. Flow-diverting stent for ruptured intracranial dissecting aneurysm of vertebral artery. Neurosurgery. 2012;70(4):982-8; discussion 8-9. Epub 2011/09/23.

31. McAuliffe W, Wycoco V, Rice H, Phatouros C, Singh TJ, Wenderoth J. Immediate and midterm results following treatment of unruptured intracranial aneurysms with the pipeline embolization device. AJNR Am J Neuroradiol. 2012;33(1):164-70. Epub 2011/10/08.

32. Ducruet AF, Crowley RW, Albuquerque FC, McDougall CG. Reconstructive endovascular treatment of a ruptured vertebral artery dissecting aneurysm using the Pipeline embolization device. J Neurointerv Surg. 2013;5(4):e20. Epub 2012/06/22.

33. McAuliffe W, Wenderoth JD. Immediate and Midterm Results Following Treatment of Recently Ruptured Intracranial Aneurysms with the Pipeline Embolization Device. AJNR Am J Neuroradiol. 2011. Epub 2011/12/03.

34. Wong GK, Poon WS. Why current evidence is against flow diverters for treatment of carotid blowout syndrome. Eur J Radiol. 2013;82(1):191. Epub 2012/02/03.

35. Fiorella D, Hsu D, Woo HH, Tarr RW, Nelson PK. Very late thrombosis of a pipeline embolization device construct: case report. Neurosurgery. 2010;67(3 Suppl Operative):onsE3134; discussion onsE4. Epub 2010/08/04. 


\section{FIGURE LEGENDS}

Fig. 1: Patient 2.

(a) DSA shows a petrosal ICA pseudoaneurysm (white arrow) with stenosis in the proximal segment (black arrow);

(b) After angioplasty with stenting of the stenotic segment and PED placement;

(c) CT brain at day 1 post-operation shows multiple ischemic infarctions.

Fig. 2: Patient 5 treated with the PED with adjuvant coiling.

(a) Diagnostic DSA shows an 8 x 14mm left petrous ICA pseudoaneurysm;

(b) Obliteration of the pseudoaneurysm sac after placement of 2 PEDs and coil;

(c) Follow-up DSA at 8-month shows the obliteration of the pseudoaneurysm and a patent parent artery.

Fig.3: Patient 6

(a) DSA shows a pseudoaneurysm at the right petrous ICA;

(b) Follow-up CTA at 3-month demonstrates telescoping of the PED and the obliteration of the pseudoaneurysm with a patent parent artery. 


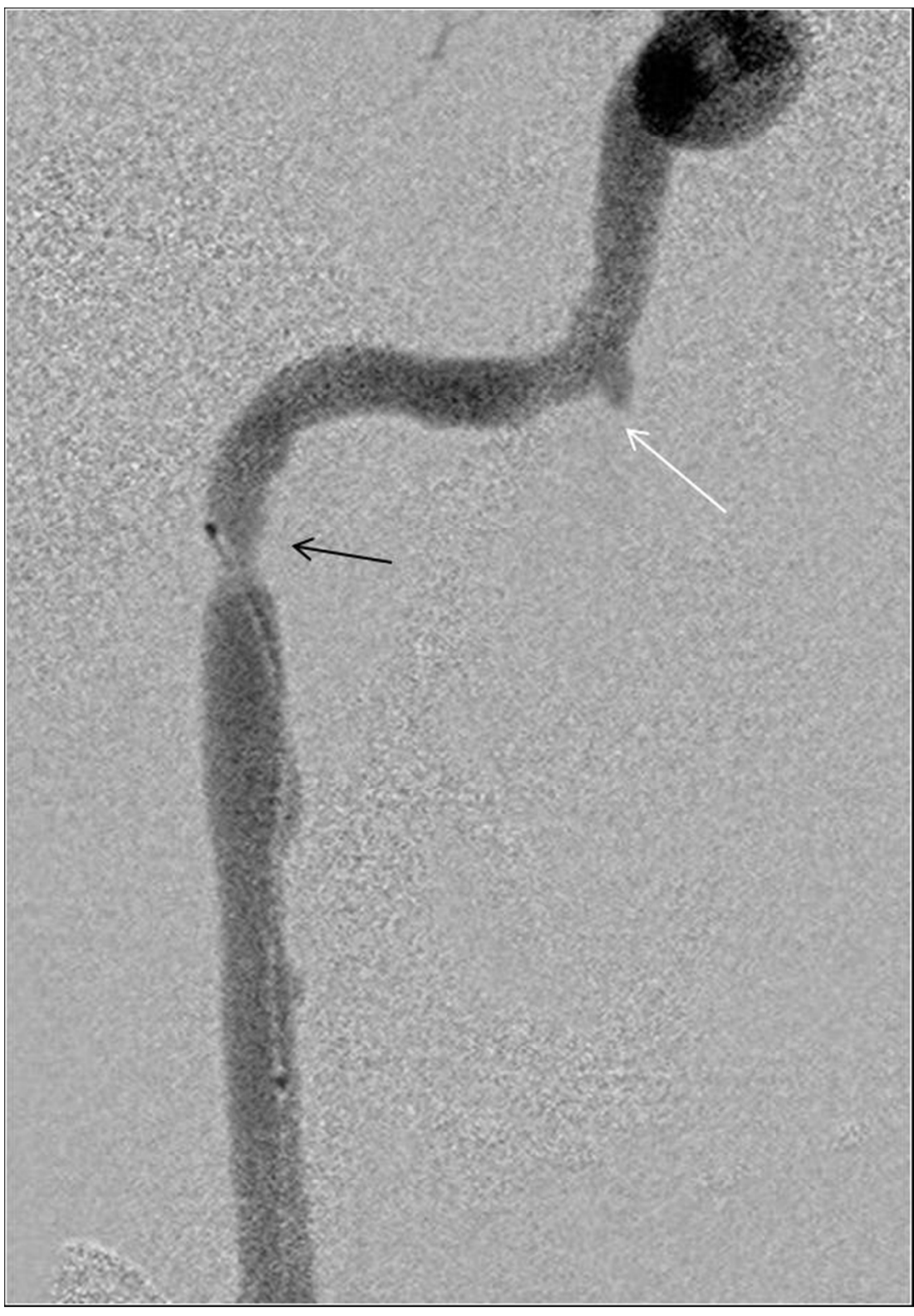

Patient 2. DSA shows a petrosal ICA pseudoaneurysm (white arrow) with stenosis in the proximal segment (black arrow);

$108 \times 155 \mathrm{~mm}(150 \times 150 \mathrm{DPI})$ 


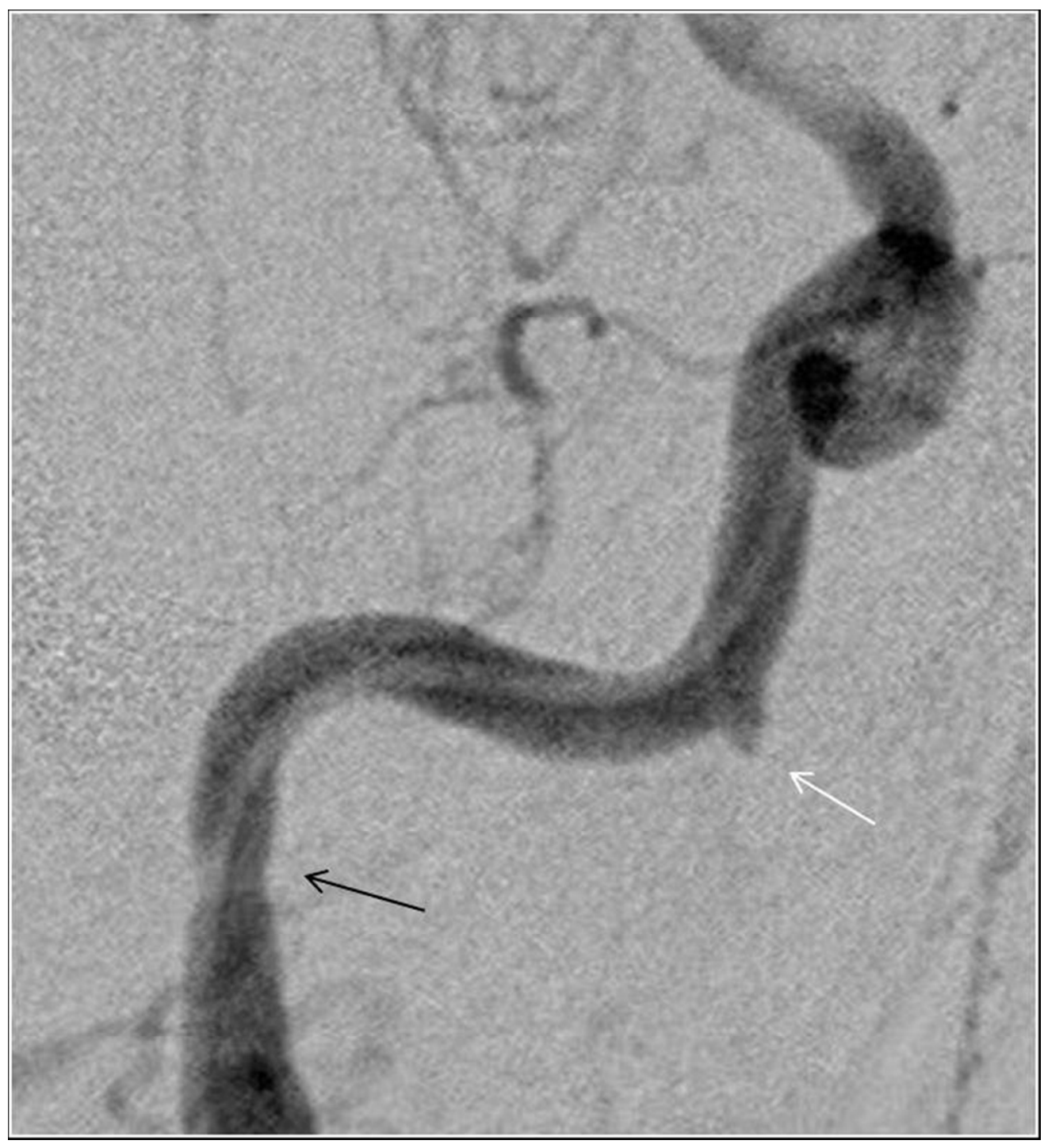

After angioplasty with stenting of the stenotic segment and PED placement $119 \times 130 \mathrm{~mm}(150 \times 150 \mathrm{DPI})$ 


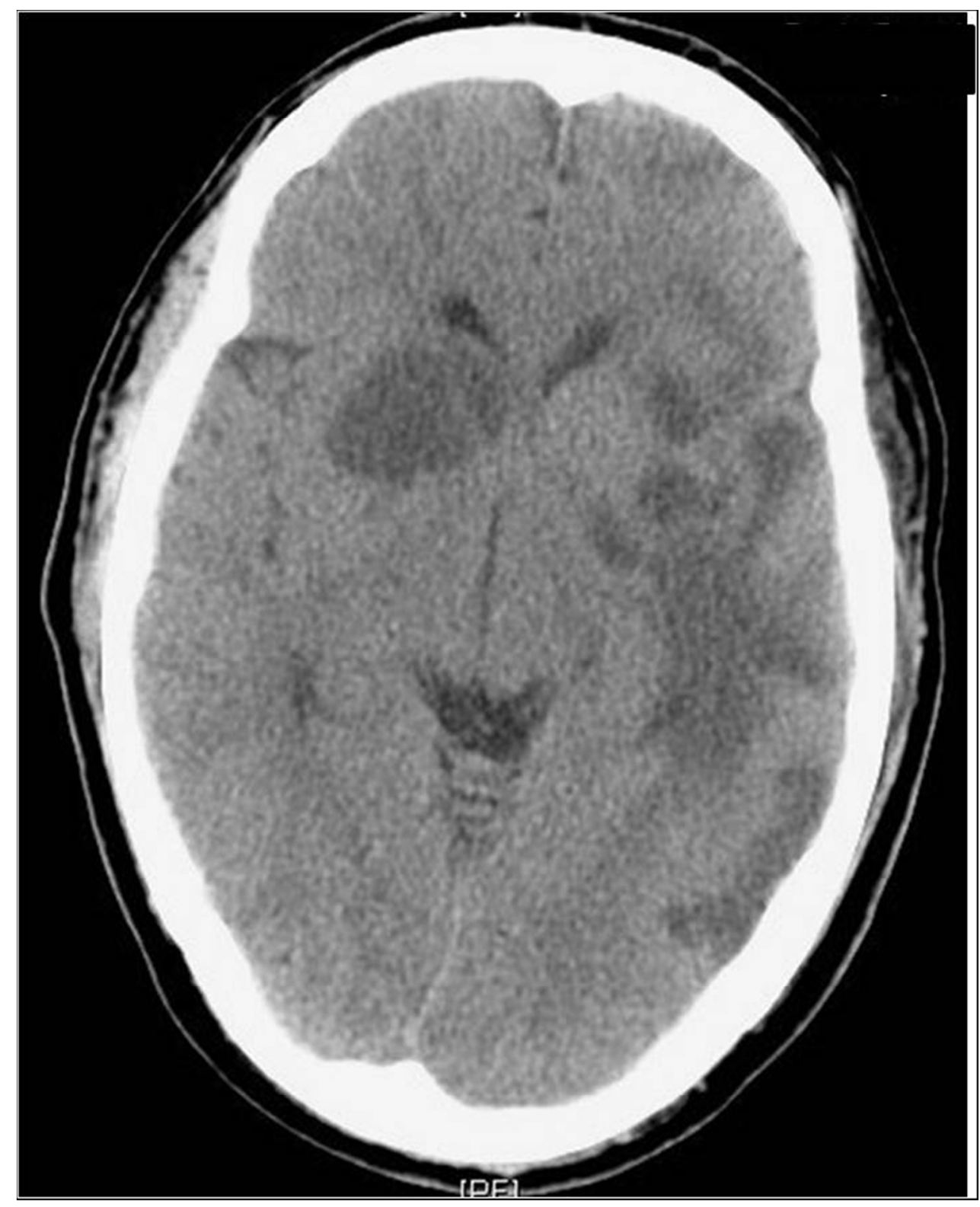

CT brain at day 1 post-operation shows multiple ischemic infarctions. $121 \times 149 \mathrm{~mm}(150 \times 150 \mathrm{DPI})$ 


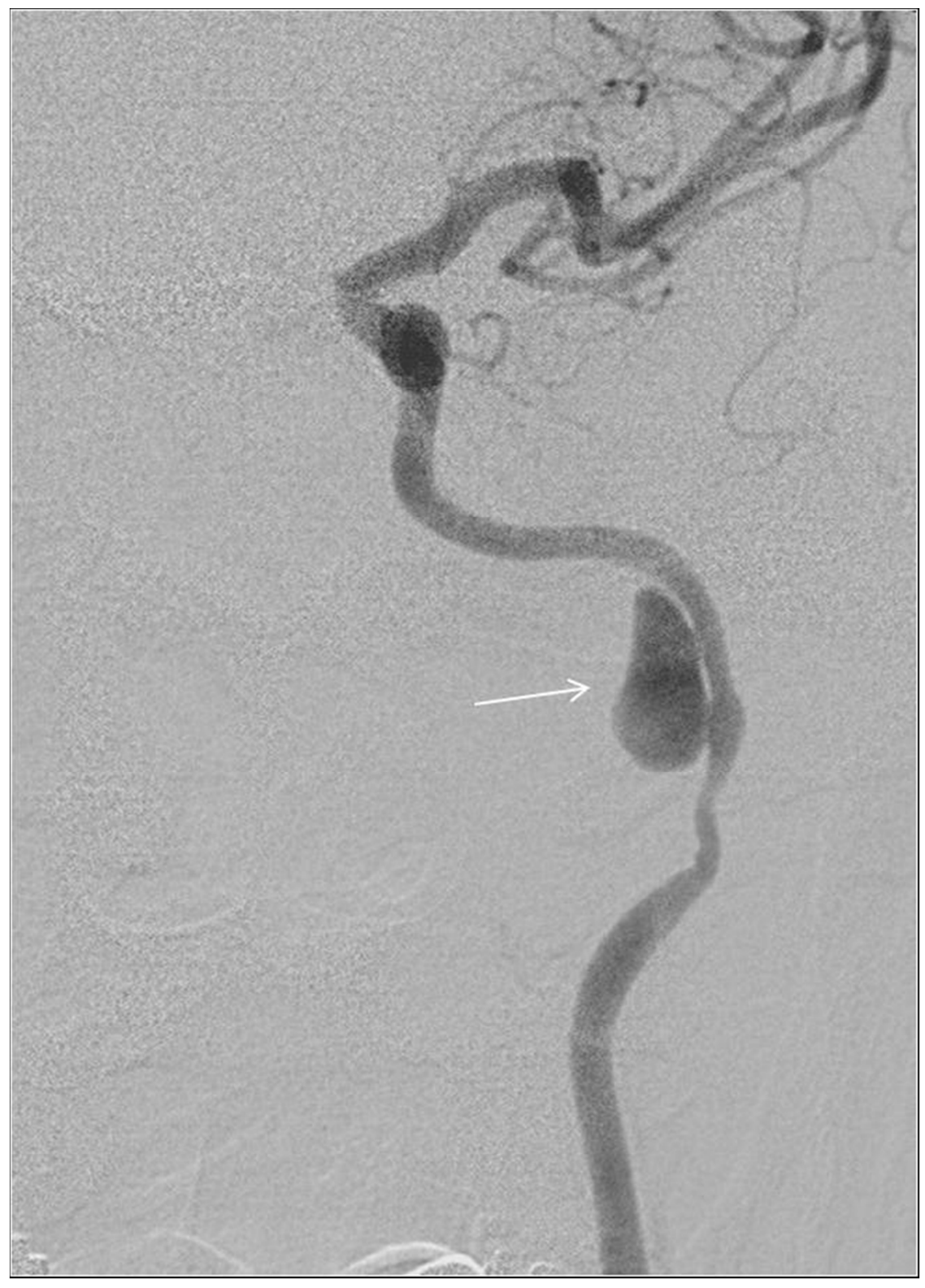

Patient 5 treated with the PED with adjuvant coiling. Diagnostic DSA shows an $8 \times 14 \mathrm{~mm}$ left petrous ICA pseudoaneurysm;

$110 \times 153 \mathrm{~mm}(150 \times 150 \mathrm{DPI})$ 
Page 19 of 22

Journal of Neurolnterventional Surgery

$$
\begin{aligned}
& 1 \\
& 2 \\
& 3 \\
& 4 \\
& 5 \\
& 6 \\
& 7 \\
& 8 \\
& 9 \\
& 10 \\
& 11 \\
& 12 \\
& 13 \\
& 14 \\
& 15 \\
& 16 \\
& 17 \\
& 18 \\
& 19 \\
& 20 \\
& 21 \\
& 22 \\
& 23 \\
& 24 \\
& 25 \\
& 26 \\
& 27 \\
& 28 \\
& 29 \\
& 30 \\
& 31 \\
& 32 \\
& 33 \\
& 34 \\
& 35 \\
& 36 \\
& 37 \\
& 38 \\
& 39 \\
& 40 \\
& 41 \\
& 42 \\
& 43 \\
& 44 \\
& 45 \\
& 46 \\
& 47 \\
& 48 \\
& 49 \\
& 50 \\
& 51 \\
& 52 \\
& 53 \\
& 5 \\
& \hline
\end{aligned}
$$

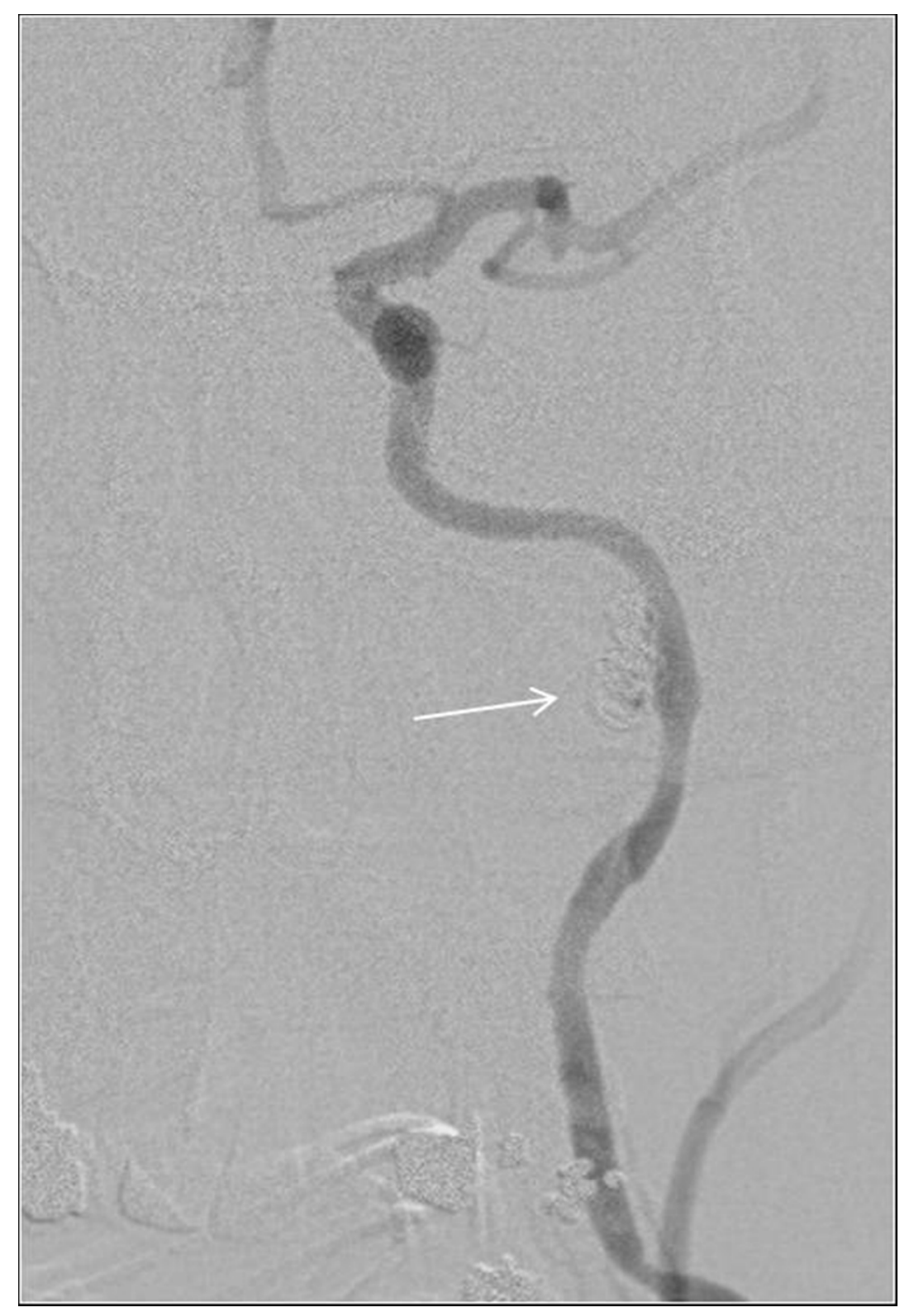

Obliteration of the pseudoaneurysm sac after placement of 2 PED and coil $85 \times 125 \mathrm{~mm}(150 \times 150 \mathrm{DPI})$

http://mc.manuscriptcentral.com/jnis 


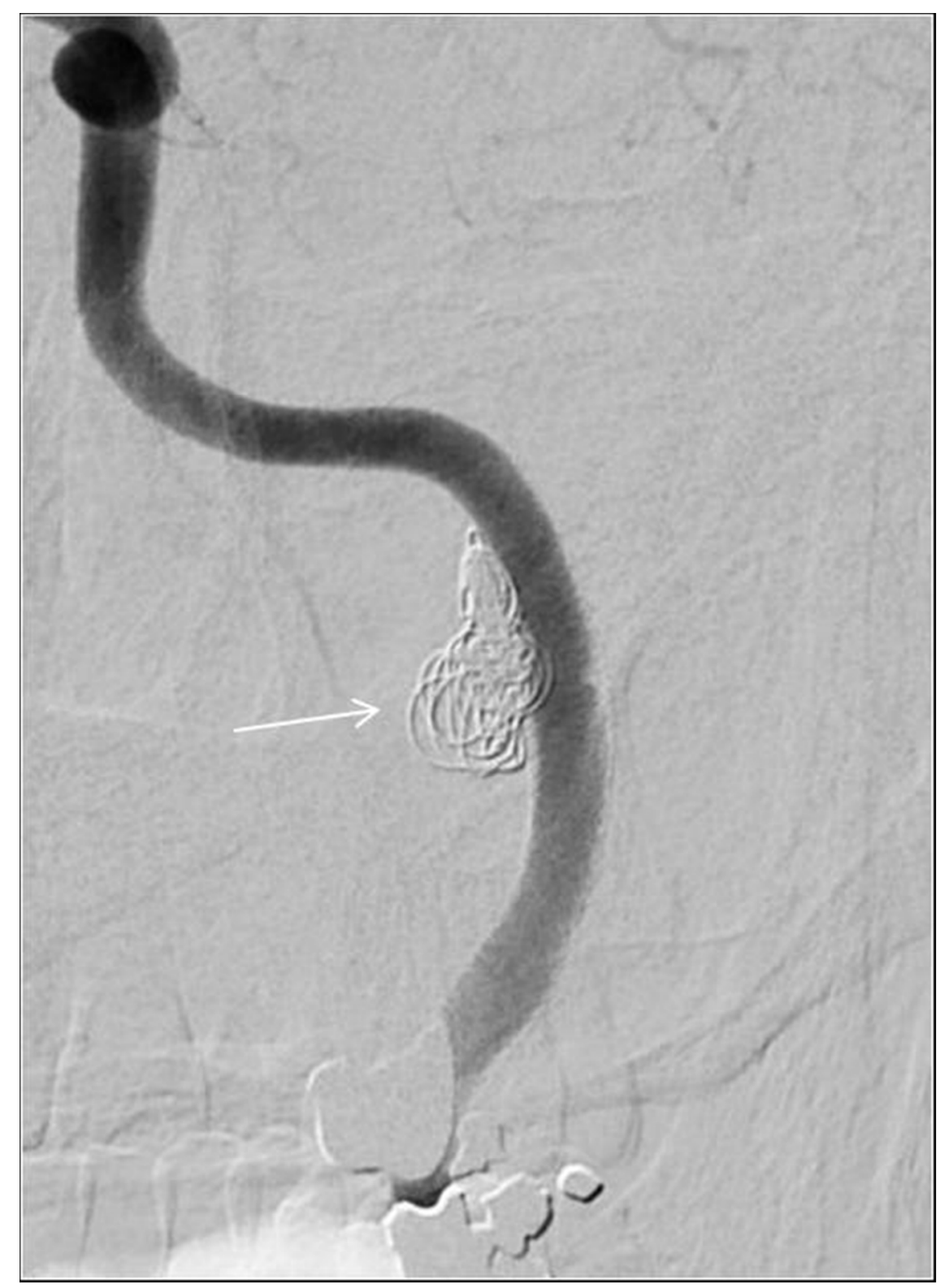

Follow-up DSA at 8-month shows the obliteration of the pseudoaneurysm and a patent parent artery. $87 \times 120 \mathrm{~mm}(150 \times 150 \mathrm{DPI})$ 


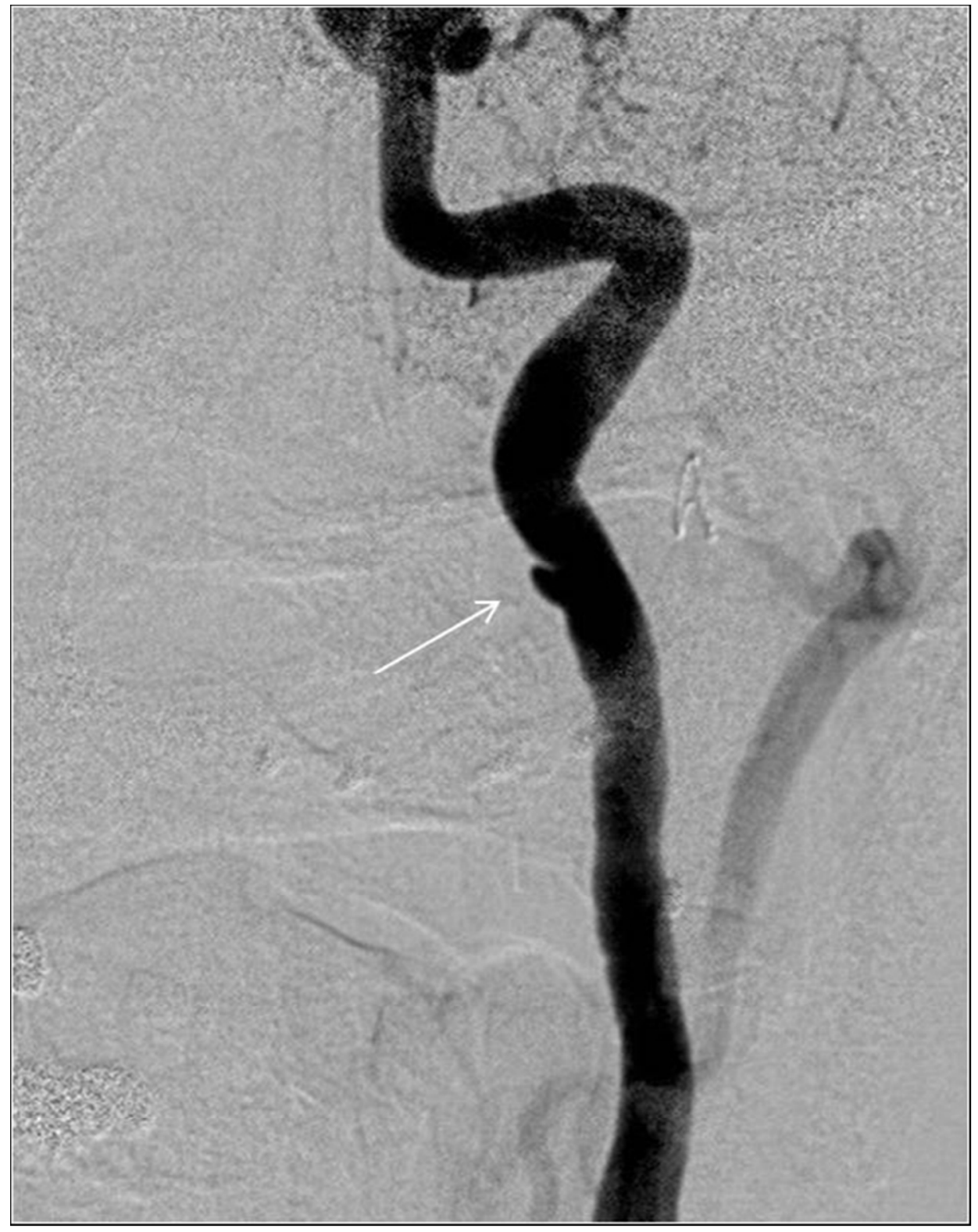

Patient 6. DSA shows a pseudoaneurysm at the right petrous ICA; $106 \times 135 \mathrm{~mm}(150 \times 150 \mathrm{DPI})$ 


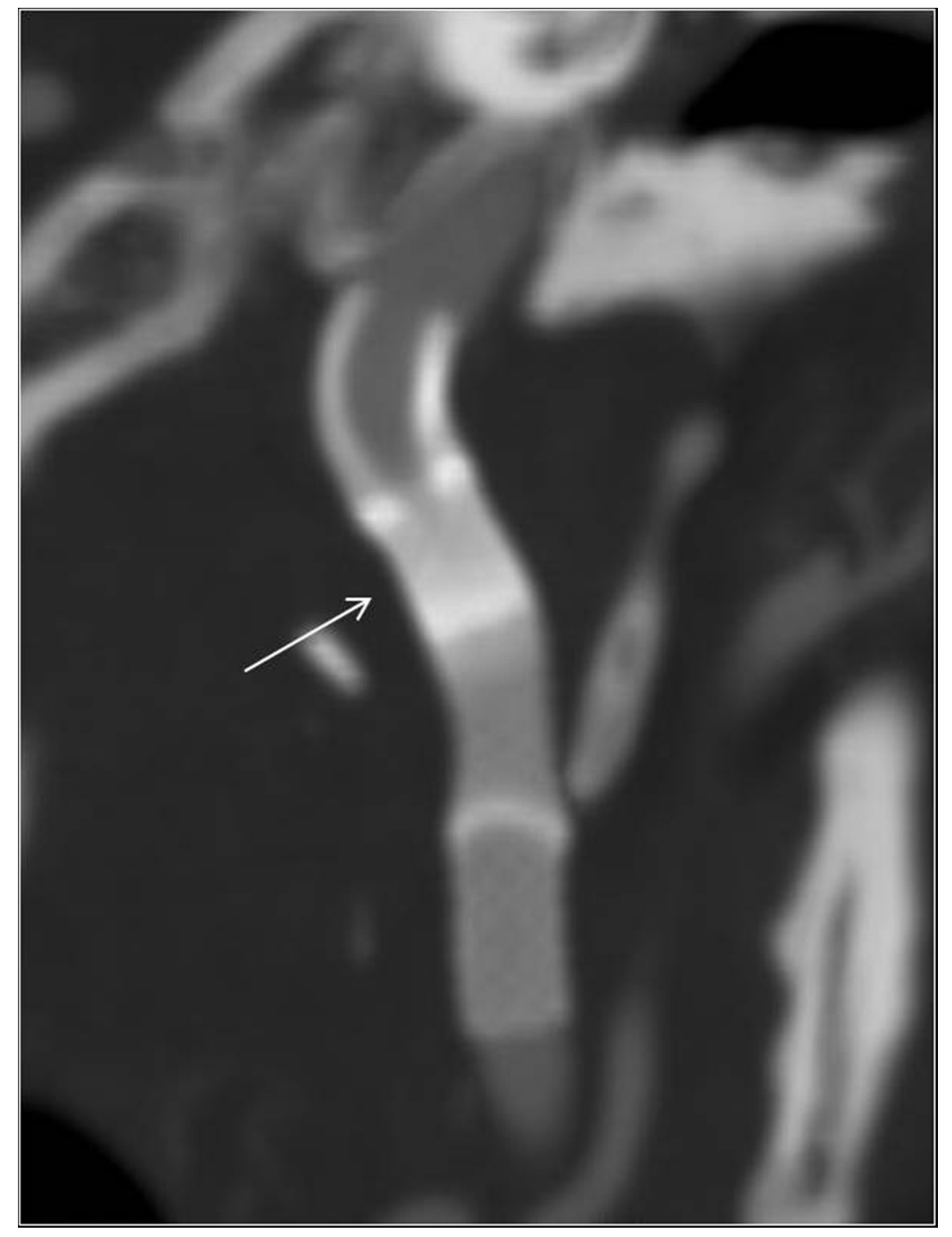

Follow-up CTA at 3-month demonstrates telescoping of the PED and the obliteration of the pseudoaneurysm with a patent parent artery. $101 \times 134 \mathrm{~mm}(150 \times 150 \mathrm{DPI})$ 